\title{
Quantitation of L-Arginine and Asymmetric Dimethylarginine in Human Plasma by LC-Selective Ion Mode-MS for Type 2 Diabetes Mellitus Study
}

\author{
Lunzhao YI, ${ }^{*, a}$ Pengfei Zhang,,${ }^{b, \#}$ Xiaoyan $\mathrm{J}_{\mathrm{I}},{ }^{a}$ Yizeng LiAng, ${ }^{a}$ Yamin WAnG, ${ }^{a}$ Zhiguang Zhou, ${ }^{c}$ and \\ Benmei $\mathrm{CHEN}^{d}$ \\ ${ }^{a}$ Research Center of Modernization of Chinese Herbal Medicine, College of Chemistry and Chemical Engineering, Central \\ South University; Changsha 410083, China: ${ }^{b}$ Key Laboratory of Cancer Proteomics of Chinese Ministry of Health, \\ Xiangya Hospital, Central South University; ' Analytical Testing Center of School of Xiangya Medicine, Central South \\ University; Changsha 410078, China: and ${ }^{c}$ Diabetes Center, The Second Xiangya Hospital, Central South University; \\ Changsha 410011, China. Received December 16, 2010; accepted March 31, 2011; published online April 11, 2011
}

The article reports a simple, sensitive and fast LC/MS method for the analysis of L-arginine (L-Arg), asymmetric dimethylarginine (ADMA) and symmetric dimethylarginine (SDMA) in human plasma. The homoarginine was used as the internal standard (IS). The chromatographic separation was achieved on $\mathrm{C}_{18}(150 \mathrm{~mm} \times$ $2.1 \mathrm{~mm}, 5 \mu \mathrm{m})$ column with a mobile phase consisting of ammonium acetate $(0.25 \mathrm{mmol} / \mathrm{l})$ and methanol $(93: 7$, $\mathrm{v} / \mathrm{v}$ ), at a flow rate of $0.2 \mathrm{ml} / \mathrm{min}$. L-Arg, ADMA and SDMA were well separated by LC/MS with selective ion mode (SIM). The method was successfully applied to type 2 diabetes mellitus (T2DM) study. Twenty-one healthy controls and twenty-two T2DM patients before and after treatment two years were investigated. The results indicated that the level of ADMA in T2DM was significantly higher than that in healthy controls. Furthermore, ADMA has important association with the development of cardiovascular diseases.

Key words asymmetric dimethylarginine; L-arginine type 2 diabetes mellitus; LC/MS

Asymmetric dimethylarginine (ADMA) and its inactive stereoisomer symmetric dimethylarginine (SDMA) are hydrolysation products of proteins with methylated arginine residues ${ }^{1)}$ which are synthesized by endothelial cells, circulated in human plasma and excreted in the urine. ${ }^{2)}$ Nitric oxide (NO) is known as the star molecule due to its pleiotropic effects on physiology, for example, relaxing vessels, decreasing the blood pressure ${ }^{3)}$ and adjusting insulin. ${ }^{4)}$ L-Argnine (L-Arg) serves as a substrate for the enzyme NO synthesis (NOS), whereas ADMA is an endogenous NOS inhibitor $^{2)}$ and a competitive inhibitor of the cellular L-Arg uptake. ${ }^{1)}$ It reduces nitric oxide production, which causes the dysfunction of endothelium and cardiovascular disease. ${ }^{5)}$ In human, SDMA is produced in equivalent quantities, although it has no direct inhibitory effect on NO synthesis." ${ }^{6}$ Clinic cases have proved that the level of ADMA is related with cardiovascular disease and ADMA may be a new biomarker in cardiovascular diseases. ${ }^{7)}$ In addition, Rask-Madsen et al. ${ }^{4)}$ found ADMA was associated with insulin resistance and diabetes to some extent. There is a growing literature implicating ADMA as a key player in endothelial dysfunction.

Therefore, accurate and reliable quantification of these substances in plasma is essential for clinical significance. Nowadays, many methods for determination of L-Arg and ADMA have been reported. ${ }^{8-13)}$ Among these methods, high-performance liquid chromatography (HPLC) might be the most widely used one. Furthermore, the $o$-phthaldialdehyde $(\mathrm{OPA})^{8)}$ and 4-fluoro-7-nitro-2,1,3-benzoxadiazole $(\mathrm{NBD}-\mathrm{F})^{9)}$ and the other derivatization reagents pre-column fluorescence derivatization technique ${ }^{10,11)}$ are employed to increase the detectability in all the reported HPLC methods. These methods are time-consuming and lack of selectivity. ${ }^{14)}$ Although the analytical time of the capillary electrophoresis is short, the sample preparation is tedious. ${ }^{12)}$ Given these shortcomings of existing techniques, our purpose is to develop a simple, sensitive and fast LC/MS method for determination of ADMA in human plasma and to estimate the re- lationship between ADMA and type 2 diabetes mellitus (T2DM).

\section{Experimental}

Reference Compounds and Chemicals L-Arginine (purity $>99.0 \%$ ), ADMA (purity $>99.0 \%$ ), SDMA (purity $>99.0 \%$ ) and L-homoarginine (purity $>99.0 \%$ ) were purchased from Sigma (St. Louis, MO, U.S.A.). HPLC grade acetonitrile was purchased from Laboratories Ltd. (Caledon, Canada) and methanol was obtained from Hanbon Sci. and Tec. of Jiangsu (China). All used water was Milli-Q grade.

Equipment The HPLC system consisted of a Shimadzu LC-10Advp pump, an SCL-10Advp system controller, a CTO-10Avp column oven, an FCV-10Advp low-pressure gradient unit, a DGU-14A degasser (Shimadzu, Kyoto, Japan). The mass spectrometer was an LC/MS-2010 single quadrupole equipped with electrospray ionization interface (Shimadzu, Kyoto, Japan). The data was collected and processed using LC/MS Solution software (version 2.02).

Chromatographic Conditions Chromatographic separation was performed using a Thermo Hypersil-Keystone Hypurity $\mathrm{C}_{18}(150 \mathrm{~mm} \times 2.1 \mathrm{~mm}$, $5 \mu \mathrm{m})$ analytical column. The oven temperature was set at $40^{\circ} \mathrm{C}$. The mobile phase containing $0.25 \mathrm{mmol} / 1 \mathrm{ammonium}$ acetate (adjusted $\mathrm{pH}$ to 2.97 with formic acid)-methanol (93:7, v/v) was used at a flow rate of $0.2 \mathrm{ml} / \mathrm{min}$.

Mass Spectrometer Conditions An LC/MS-2010 quadrupole mass spectrometer was interfaced with electrospray ionization (ESI) probe. The temperatures were maintained at $250{ }^{\circ} \mathrm{C}$ and $200^{\circ} \mathrm{C}$ for the Curved Desolvation Line $(\mathrm{CDL})$ and block, respectively. The voltages were set at $4.5 \mathrm{kV}$ and $1.6 \mathrm{kV}$ for the probe and detector, respectively. The flow rate of nebuliser gas $\left(\mathrm{N}_{2}\right)$ and dried gas were set at $1.5 \mathrm{l} / \mathrm{min}$ and $10 \mathrm{l} / \mathrm{min}$, respectively. The analyte was detected by the selected positive-ion monitoring mode. The ions of selection monitoring were decided by positive scanning from $\mathrm{m} / \mathrm{z} 100$ 1000. For the quantification of target analytes of L-Arg, ADMA, SDMA, L-homoarginine internal standard (IS), the positive protonated molecule ions of L-Arg at $m / z=231[\mathrm{M}+\mathrm{H}]^{+}$, ADMA at $259[\mathrm{M}+\mathrm{H}]^{+}$, SDMA at 259 $[\mathrm{M}+\mathrm{H}]^{+}$and IS at $245[\mathrm{M}+\mathrm{H}]^{+}$were monitored. Tuning of mass spectrometer was performed with the help of autotuning function of LC/MS Solution software (version 2.02) using tuning standard solution (polyethylene glycol).

Preparation of Stock Solutions A stock solution of ADMA, SDMA, LArg, and IS in water (Milli-Q grade) at concentration of $0.2 \mathrm{mmol} / \mathrm{l}$, $0.2 \mathrm{mmol} / 1,5.0 \mathrm{mmol} / 1$ and $5.0 \mathrm{mmol} / 1$ were prepared, respectively. The IS solution was prepared by the addition of $10 \mu \mathrm{l}$ IS $(5.0 \mathrm{mmol} / \mathrm{l})$ to a $1 \mathrm{ml}$ volumetric flask and brought to volume with Milli-Q grade water $(50 \mu \mathrm{mol} / \mathrm{l})$.

Calibration Standard Seven levels of calibration were prepared for ADMA and L-Arg. The highest calibration was prepared by the addition of 
$20 \mu \mathrm{l}$ (ADMA) and $32 \mu \mathrm{l}$ (L-Arg) to a volumetric flask with $748 \mu \mathrm{l}$ water (Milli-Q grade). Calibration standards were prepared by serial dilution of the highest calibration level for the desired calibration range. Seven levels of calibration were used for quantification, including a blank, prepared at concentrations of $0.08,0.16,0.3,0.6,1.25,2.5,5 \mu \mathrm{mol} / 1$ for ADMA, and 3.125, $6.25,12.5,25,50,100,200 \mu \mathrm{mol} / 1$ for L-Arg. Quality control (QC) samples (for accuracy and precision) were prepared at a concentration of $0.5 \mu \mathrm{mol} / 1$ (low), $2.0 \mu \mathrm{mol} / 1$ (media), $4.0 \mu \mathrm{mol} / 1$ (high) for ADMA and $5 \mu \mathrm{mol} / 1$, $50 \mu \mathrm{mol} / 1,100 \mu \mathrm{mol} / 1$ for L-Arg. All standard stock solutions were stored at $-20{ }^{\circ} \mathrm{C}$.

Collection and Preparation of the Samples Twenty-one healthy volunteers ( 11 male and 10 female, $24-78$ years old) and twenty-two type 2 diabetes mellitus patients ( 12 male and 10 female, 26-67 years old) accepted the investigation. Their informed consent was obtained before enrollment Blood samples were collected in heparinized tubes. Plasma was immediately separated by centrifugation at $3000 \mathrm{rpm}$ for $10 \mathrm{~min}$ and store at $-80^{\circ} \mathrm{C}$ until analysis. A plasma sample $(0.1 \mathrm{ml})$ was placed in a $1.5 \mathrm{ml}$ Eppendorf tube. Ten microliter aliquots of homoarginine (IS $50 \mu \mathrm{mol} / 1$ ) standard solution and $300 \mu \mathrm{l}$ of acetonitrile were added and vortex-mixed. The precipitate protein was removed by centrifugation at $15000 \mathrm{rpm}$ for $5 \mathrm{~min}$ and the organic phase was transferred to another clear $1.5 \mathrm{ml}$ Eppendorf tube. The extract was evaporated to dryness under gentle nitrogen stream at $65^{\circ} \mathrm{C}$. Then the residue was added $200 \mu \mathrm{l}$ of $1 \mathrm{~mol} / 1$ of $\mathrm{HCl} / n$-butanol and reacted for $15 \mathrm{~min}$ at $65^{\circ} \mathrm{C}$. After decreased to the room temperature, the Eppendorf tube was centrifuged at $15000 \mathrm{rpm}$ for $5 \mathrm{~min}$ at room temperature and the supernatant was transferred to another clean $1.5 \mathrm{ml}$ Eppendorf tube. The extract was evaporated to dryness under gentle nitrogen stream at $65^{\circ} \mathrm{C}$. The residue was redissolved in $50 \mu \mathrm{l}$ of mobile phase and $10 \mu \mathrm{l}$ of solution was injected in to the analytical column.

Statistical Analysis Results are presented as means \pm S.D. betweengroup differences and comparisons between healthy controls and T2DM were evaluated by $t$-test.

\section{Results and Discussion}

Results The LC/MS method proposed in this work was a simple procedure for the simultaneous separation and determination of L-Arg, ADMA and SDMA in human plasma. Since the chemical structures and MS spectra of the positional isomers (ADMA and SDMA) were quite similar, their separation was very difficult. Figure 1 showed the chromatogram of ADMA and SDMA standards. The peaks of ADMA and SDMA were seriously over-lapped. For the separation of these two components, the pretreatment and chromatographic conditions were optimazed. Though some publications have reported the un-derivatization methods of ADMA, the results we obtained were not as good as the references. ${ }^{15,16)}$ For that reason, derivization methods were employed. Derivatization methods were commonly used in separation and determination of hydrophilic analytes. In this study, three different derivations were evaluated, including isopropanol, $n$-butanol and $n$-octanol. The polarity of component after derivazition with $n$-octanol will be decreased sig-

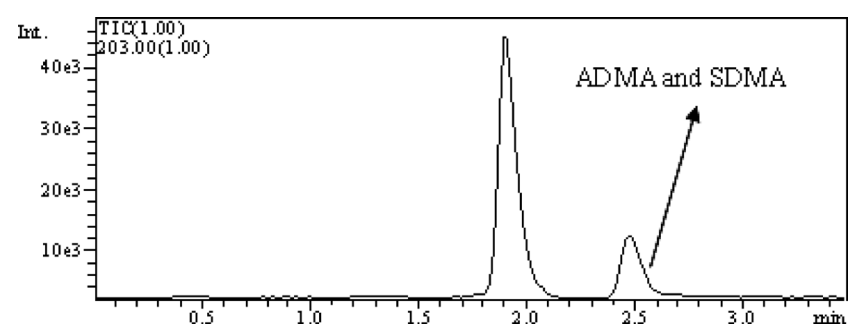

Fig. 1. LC/MS Chromatogram of Non-derivatized ADMA and SDMA Standards' Mixture Using an ESI Interface in Selected Positive Ion Monitoring Mode by Scanning $m / z 203$ in Different Mobile Phase

(A) Twenty micromolar ammonium acetate $(\mathrm{pH}=3.9,95 \%)$, (B) methanol $(5 \%)$ Column: Thermo Hypersil-Hypurity $\mathrm{C}_{18}(150 \mathrm{~mm} \times 2.1 \mathrm{~mm}, 5 \mu \mathrm{m})$. nificantly, which make the elution of derivatives much harder, retention time increasing. The spatial stereoscopic effect of isopropanol, ADMA and SDMA is strong, which decreases the derivatization efficiency significantly. $n$-Butanol can decrease the polarity of component with weak spatial stereoscopic effect. After comparison, it was found that $n$ butanol was the best one for its higher efficiency and shorter retention time.

Chromatographic condition, based on the isocratic separation, gave a very good profile for plasma using a reverse phase Thermo Hypersil-Keystone Hypurity $\mathrm{C}_{18}(150 \mathrm{~mm} \times$ $2.1 \mathrm{~mm}, 5 \mu \mathrm{m}$ ) column. Different ratios of mobile phase were then studied in order to shorten retention times of analytes and to improve peak symmetry. Best results in terms of peak symmetry and retention time were obtained using ammonium acetate $(0.25 \mathrm{mmol} / \mathrm{l})$ and methanol $(93: 7, \mathrm{v} / \mathrm{v})$ as mobile phase. The $\mathrm{pH}$ of the mobile phase was adjusted with formic acid to 2.97. Figures 2 and 3 have shown the chromatograms of the derivatized ADMA and SDMA, L-homoarginine (IS), respectively, according to the above experimental conditions discussed in 'Chromatographic Condi-
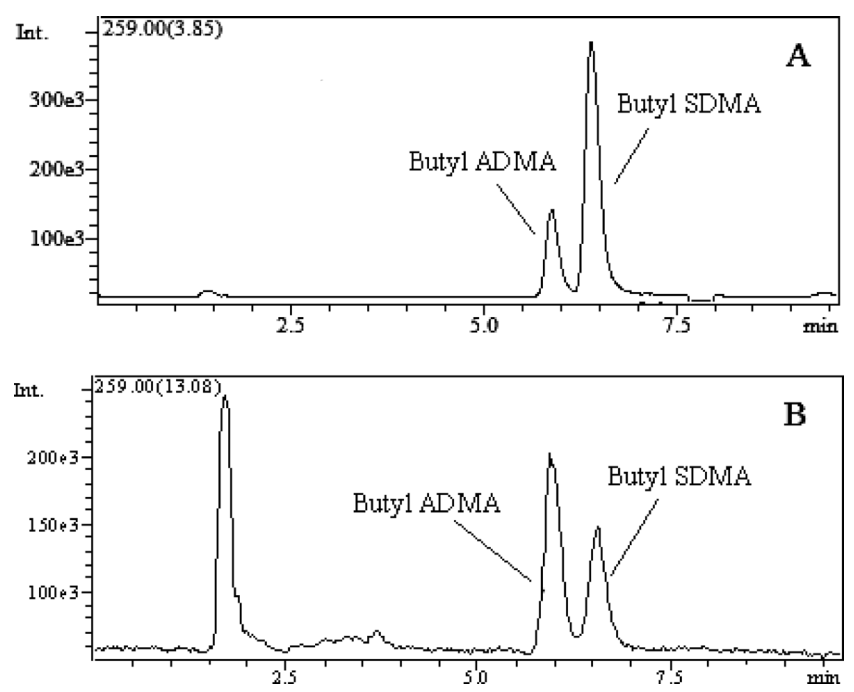

Fig. 2. Chromatogram of the Derivatized ADMA and SDMA Standards (A), Chromatogram of the Derivatized ADMA and SDMA of Plasma (B)
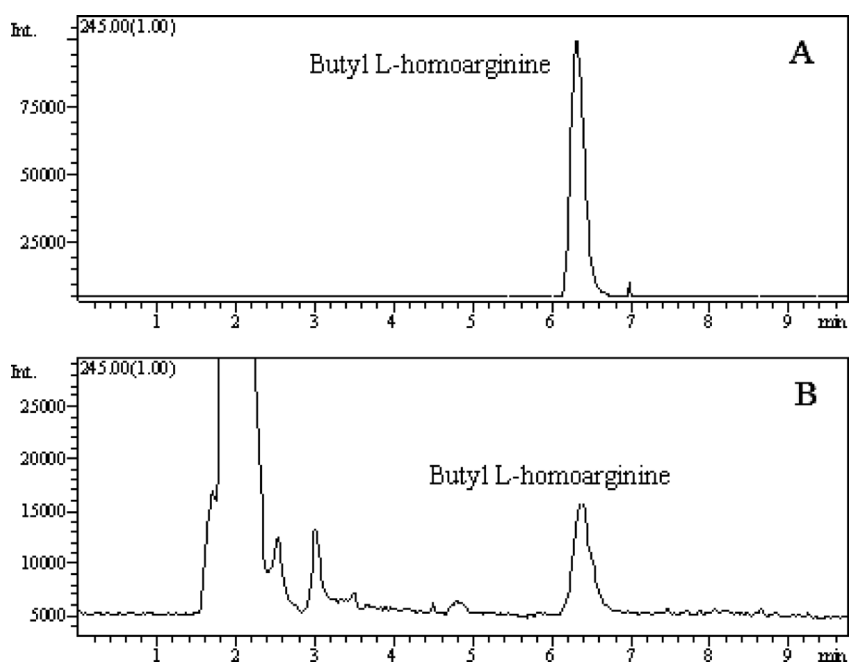

Fig. 3. Chromatogram of the Derivatized L-Homoarginine Standard (A), Chromatogram of the Derivatized L-Homoarginine of Plasma (B) 
tions,' 'Mass Spectrometer Conditions' and 'Collection and Preparation of the Samples.' The peak was symmetric and sharp, and its $[\mathrm{M}+\mathrm{H}]^{+}$was totally different from the analyte. The chromatograms in different charge mass ratios of a representative human plasma sample were showed in Fig. 4. The chromatograms of LC-ESI-MS in SIM mode was unaffected by the impurities (such as other amino acids) at all and it could be used to clearly identify the target components. It could provide better defined peaks for the detected compounds with its low limits of detection and quantification. Using the optimized method, less than $40 \mathrm{~min}$ is needed for pretreatment and chromatographic separation of one plasma sample. It is simple, sensitive and fast when compared with others, ${ }^{17-25)}$ shown in Table 1.

Method Validation. Linearity of Calibration Curve and Limit of Quantitation The standards were derivatized by the procedure described in 'Collection and Preparation of the Samples' and the standard curves were calculated by plotting the ratio of peak areas against concentrations of L-Arg and ADMA. Typical linear regression equations from standard curves for each analyte were: L-Arg $\left(Y_{\mathrm{L}-\mathrm{Arg}}=0.4716 X+\right.$ $0.9052)$ and $\operatorname{ADMA}\left(Y_{\mathrm{ADMA}}=0.5798 X-0.0648\right)$ where $Y$ was

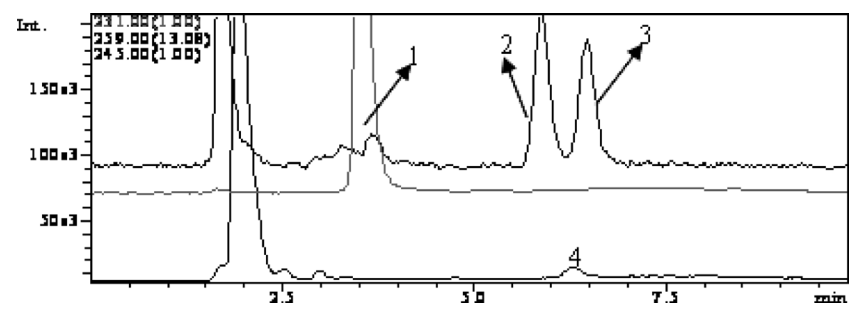

Fig. 4. Typical Chromatograms of Plasma

(1) L-Arg; (2) ADMA; (3) SDMA; (4) L-homoarginine. Column: Thermo HypersilKeystone Hypurity $\mathrm{C}_{18}(150 \mathrm{~mm} \times 2.1 \mathrm{~mm}, 5 \mu \mathrm{m})$; flow-rate: $0.2 \mathrm{ml} / \mathrm{min}$; mobile phase: ammonium acetate and methanol $(93: 7, \mathrm{v} / \mathrm{v})$. the peak ratio of analyte to internal standard and $X$ was the analyte concentration in $\mu \mathrm{mol} / 1$. The correlation coefficients were 0.9991 for L-Arg and 0.9987 for ADMA. The calibration functions were linear in the range of $3-200 \mu \mathrm{mol} / 1$ for L-Arg and $0.08-5.0 \mu \mathrm{mol} / 1$ for ADMA. The limits of quantitation were $3.0 \mu \mathrm{mol} / 1$ for $\mathrm{L}-\mathrm{Arg}(\mathrm{S} / \mathrm{N}>10)$ and $0.08 \mu \mathrm{mol} / 1$ for ADMA $(\mathrm{S} / \mathrm{N}>10)$.

Precision, Accuracy and Extraction Recovery Interday precision was determined by repeating sample preparation and LC-MS analysis of QC samples at each concentration level for three times on three consecutive days. Intra-day precision was determined by analyzing QC samples at each concentration level for three times within $1 \mathrm{~d}$. The data from inter- and intra-day precision measurements was used to calculate the accuracy. Tables 2 and 3 showed the intra- and inter-day precision and extraction recovery for L-Arg and ADMA, respectively.

Stability As specimens were usually handled and transported to the laboratory at room temperature, we thus tested the plasma stored at room temperature for $4 \mathrm{~h}$. Hypothesis testing of equal variance was used to calculate $p$ value. The concentration of ADMA showed significant difference. It indicated that ADMA in plasma is unstable at room temperature (about $35^{\circ} \mathrm{C}$ ). So the plasma should be handled immediately after thawed. We also tested the stability of the plasma between the frozen-thawed processes. There was no variability before frozen and after thawed for 4 times. Tables 4 and 5 showed the stability of plasma at room temperature and the stability of plasma before frozen and after thawed, respectively.

Application of the Method The proposed method was successfully applied to plasma samples (21 healthy controls and 22 T2DM). The concentrations of L-Arg and ADMA were listed in Table 6. The concentration of SDMA was calculated by graphing the ratio of peak area (SDMA) to area of

Table 1. Pretreatment Time of ADMA of Different Methods

\begin{tabular}{|c|c|c|c|}
\hline The first author of reference & Method & Pretreatment time $(\mathrm{h})$ & LC-MS analysis (min) \\
\hline Vishwanathan $^{15)}$ & LC-MS no derivatization & 0.25 & 15 \\
\hline Tsikas $^{17)}$ & GC-MS-MS, derivatization & 2.5 & 11 \\
\hline Martens-Lobenhoffer ${ }^{18)}$ & LC-MS, derivatization & 1 & 32 \\
\hline Albsmeier ${ }^{19)}$ & GC-MS, derivatization & 3 & 10.8 \\
\hline Huang $^{16)}$ & LC-MS, no derivatization & 0.5 & 7 \\
\hline Martens-Lobenhoffer ${ }^{20)}$ & LC-MS, derivatization & 1 & 32 \\
\hline Kirchherr $^{21)}$ & LC-MS-MS, no derivatization & 0.25 & 6 \\
\hline Schwedhelm ${ }^{22)}$ & LC-MS-MS, derivatization & 1 & 4 \\
\hline Martens-Lobenhoffer ${ }^{23)}$ & LC-MS-MS, no derivatization & 0.2 & 8 \\
\hline Blackwell ${ }^{24)}$ & LC-FD (fluorescence detector), derivatization & 0.4 & 34 \\
\hline Our study & LC-MS, derivatization & 0.3 & 10 \\
\hline
\end{tabular}

Table 2. Intra- and Inter-Day Precision and Extraction Recovery for L-Arg

\begin{tabular}{|c|c|c|c|c|}
\hline \multirow{2}{*}{ L-Arg } & \multirow{2}{*}{ Time } & \multicolumn{3}{|c|}{ Concentration added $(\mu \mathrm{mol} / \mathrm{l})$} \\
\hline & & 25 & 50 & 100 \\
\hline \multirow{3}{*}{$\begin{array}{l}\text { Concentration found } \\
\qquad(\mu \mathrm{mol} / 1)\end{array}$} & The first day & $25.3 \pm 0.73$ & $51.5 \pm 1.48$ & $103.5 \pm 1.53$ \\
\hline & The second day & $27.0 \pm 1.06$ & $46.7 \pm 1.67$ & $97.4 \pm 0.86$ \\
\hline & The third day & $23.8 \pm 0.76$ & $48.4 \pm 0.90$ & $102.6 \pm 2.91$ \\
\hline Intra-day RSD (\%) & & 3.9 & 3.6 & 2.8 \\
\hline Inter-day RSD (\%) & & 6.2 & 4.9 & 3.2 \\
\hline Extraction recovery $(\%)$ & & 101 & 98 & 101 \\
\hline
\end{tabular}


Table 3. Intra- and Inter-Day Precision and Extraction Recovery for ADMA

\begin{tabular}{|c|c|c|c|c|}
\hline \multirow{2}{*}{ ADMA } & \multirow{2}{*}{ Time } & \multicolumn{3}{|c|}{ Concentration added $(\mu \mathrm{mol} / \mathrm{l})$} \\
\hline & & 0.5 & 2 & 5 \\
\hline \multirow{3}{*}{$\begin{array}{l}\text { Concentration found } \\
(\mu \mathrm{mol} / 1)\end{array}$} & The first day & $0.47 \pm 0.01$ & $1.77 \pm 0.05$ & $4.73 \pm 0.09$ \\
\hline & The second day & $0.42 \pm 0.02$ & $2.07 \pm 0.05$ & $4.37 \pm 0.09$ \\
\hline & The third day & $0.40 \pm 0.02$ & $1.81 \pm 0.02$ & $5.07 \pm 0.12$ \\
\hline Intra-day RSD (\%) & & 5.9 & 3.3 & 3.0 \\
\hline Inter-day RSD (\%) & & 7.8 & 7.4 & 6.5 \\
\hline Extraction recovery $(\%)$ & & 93 & 94 & 94 \\
\hline
\end{tabular}

Table 4. The Stability of Plasma at Room Temperature

\begin{tabular}{ccc}
\hline \hline Intervals of $n$ hours & L-Arg $(\mu \mathrm{mol} / 1)$ & ADMA $(\mu \mathrm{mol} / 1)$ \\
\hline$n=0$ & $45.82 \pm 1.42$ & $0.39 \pm 0.02$ \\
$n=4$ & $44.80 \pm 0.24$ & $0.46 \pm 0.02$ \\
$p$ & $p>0.05$ & $p=0.003<0.05$ \\
\hline
\end{tabular}

Table 5. The Stability of Plasma before Frozen and after Thawed

\begin{tabular}{ccc}
\hline \hline Times of frozen and thawed & L-Arg $(\mu \mathrm{mol} / \mathrm{l})$ & ADMA $(\mu \mathrm{mol} / \mathrm{l})$ \\
\hline$n=1$ & $45.82 \pm 1.14$ & $0.50 \pm 0.03$ \\
$n=4$ & $45.68 \pm 1.56$ & $0.49 \pm 0.02$ \\
$p$ & $p>0.05$ & $p>0.05$ \\
\hline
\end{tabular}

Table 6. The Concentration of L-Arg and ADMA in Healthy Controls, T2DM Patients and after Treatment 2 Years of T2DM

\begin{tabular}{lccc}
\hline \hline & $\begin{array}{c}\text { ADMA } \\
(\mu \mathrm{mol} / 1)\end{array}$ & $\begin{array}{c}\text { L-Arg } \\
(\mu \mathrm{mol} / 1)\end{array}$ & $\begin{array}{c}\text { SDMA } \\
(\mu \mathrm{mol} / 1)\end{array}$ \\
\hline Healthy controls $(n=21)$ & $0.46 \pm 0.17$ & $45.8 \pm 0.3$ & $0.47 \pm 0.26$ \\
T2DM $(n=22)$ & $0.78 \pm 0.29$ & $48.2 \pm 0.5$ & $0.45 \pm 0.15$ \\
After treatment 2 years of & $0.75 \pm 0.27$ & $46.4 \pm 0.4$ & $0.51 \pm 0.20$ \\
$\quad$ T2DM $(n=22)$ & & & \\
\hline
\end{tabular}

Table 7. The Concentrations of ADMA from References

\begin{tabular}{lccc}
\hline \hline \multirow{2}{*}{$\begin{array}{l}\text { The first author of } \\
\text { reference }\end{array}$} & Sample & \multicolumn{2}{c}{ ADMA $(\mu \mathrm{mol} / \mathrm{l})$} \\
\cline { 3 - 4 } & & T2DM & Controls \\
\hline $\begin{array}{l}\text { Krzyzanowska }^{26)} \\
\text { Makino }^{27)}\end{array}$ & Plasma & $0.55(0.48-0.62)$ & - \\
Devangelio $^{28)}$ & Serum & $1.26 \pm 0.21$ & $0.91 \pm 0.47$ \\
Fard $^{29)}$ & Plasma & $0.80(0.62-1.11)$ & $0.50(0.38-0.66)$ \\
Stühlinger $^{30)}$ & Plasma & $1.04 \pm 0.99$ & - \\
\hline
\end{tabular}

the internal standard versus concentration. The concentration of ADMA showed significant difference between healthy controls and T2DM $(p<0.05)$, The level of ADMA was much higher in T2DM patients compared to healthy controls, which indicated that ADMA had associativity with T2DM, and this was coincidence with other's research, ${ }^{26-30)}$ shown in Table 7. The concentration of SDMA and L-Arg showed no significant deviation among the three groups, which indicated that they had not associativity with T2DM $(p>0.05)$. The change of ADMA level in plasma after treated for two years was evaluated, shown in Fig. 5. ADMA levels of seven patients increased. Clinical information indicated that all

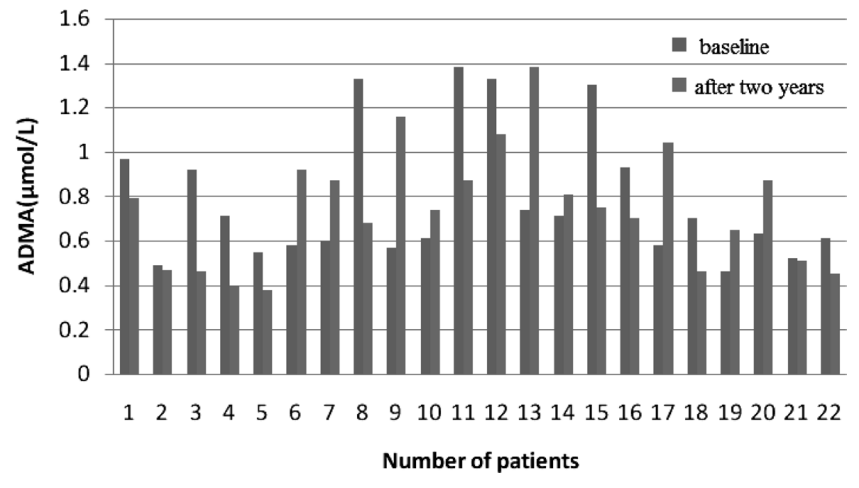

Fig. 5. Plasma ADMA Concentrations of T2DM Patients before (Baseline) and after Treatment for Two Years

these patients have combined with atherosclerosis after two years. ADMA levels of 15 patients decreased. However, 5 patients of them have atherosclerosis. These results demonstrated that ADMA has strong relationship with T2DM. Furthermore, this component has important association with the development of cardiovascular diseases. ADMA is not the only biomarker for T2DM, but a very critical one.

\section{Conclusion}

A simple, sensitive and fast liquid chromatography mass spectrometry method coupled with electro-spray ionization was developed for the simultaneous determination of L-Arg, ADMA and SDMA in human plasma. Optimal chromatographic conditions allowed the ADMA derivative to be baseline resolved from SDMA derivatives. Complex sample preparation was not required in this method and chromatograms of LC-ESI-MS in SIM mode clearly identified the target components. The run time of each determination was $10 \mathrm{~min}$. By using this method, the ADMA level of 21 healthy controls and 22 T2DM patients before and after treatment were investigated qualitatively and quantitatively, respectively. The result indicated that the level of ADMA in T2DM was significantly higher than that in healthy controls. Furthermore, this component has important association with the development of cardiovascular diseases.

Acknowledgements This work was supported financially by Special Fundation of China Postdoctoral Science (No. 200902481), Central South University Science Development Foundation (No. 10SDF22) and Advanced Research Plan of Central South University (201021200011).

\section{References}

1) Leiper J., Vallance P., Cardiovasc. Res., 43, 542-548 (1999).

2) Vallance P., Leone A., Calver A., Collier J., Moncada S., J. Cardiovasc. Pharmacol., 20 (Suppl. 12), S60-S62 (1992). 
3) Cooke J. P., Dzau V. J., Annu. Rev. Med., 48, 489-509 (1997).

4) Rask-Madsen C., King G. L., Nat. Clin. Pract. Endocrinol. Metab., 3, 46-56 (2007).

5) Cooke J. P., Arterioscler. Thromb. Vasc. Biol., 20, 2032-2037 (2000).

6) Chan N. N., Chan J. C., Diabetologia, 45, 1609-1616 (2002).

7) Ueda S., Yamagishi S. I., Matsumoto Y., Fukami K., Okuda S., Clin. Exp. Nephrol., 11, 115-121 (2007).

8) Chen B. M., Xia L. W., Liang S. X., Chen G. H., Deng F. L., Zhang W. R., Tao L. J., Anal. Chim. Acta, 444, $223-227$ (2001).

9) Nonaka S., Tsunoda M., Imai K., Funatsu T., J. Chromatogr. A, 1066, $41-45$ (2005).

10) Heresztyn T., Worthley M. I., Horowitz J. D., J. Chromatogr. B Analyt. Technol. Biomed. Life Sci., 805, 325-329 (2004).

11) Ueno S., Sano A., Kotani K., Kondoh K., Kakimoto Y., J. Neurochem., 59, 2012-2016 (1992)

12) Causse E., Siri N., Arnal J. F., Bayle C., Malatray P., Valdiguie P., Salvayre R., Couderc F., J. Chromatogr. B Analyt. Technol. Biomed. Life Sci., 471, 77-83 (2000).

13) Vallance P., Leone A., Calver A., Collier J., Moncada S., Lancet, 339, 572-575 (1992).

14) Pettersson A., Uggla L., Backman V., J. Chromatogr. B Analyt. Technol. Biomed. Life Sci., 692, 257-262 (1997).

15) Vishwanathan K., Tackett R. L., Stewart J. T., Bartlett M. G., J. Chromatogr. B Analyt. Technol. Biomed. Life Sci., 748, 157-166 (2000).

16) Huang L. F., Guo F. Q., Liang Y. Z., Hu Q. N., Cheng B. M., Anal. Chim. Acta, 487, 145-153 (2003).

17) Tsikas D., Schubert B., Gutzki F. M., Sandmann J., Frölich J. C., J. Chromatogr. B Analyt. Technol. Biomed. Life Sci., 798, 87-99 (2003).

18) Martens-Lobenhoffer J., Bode-Böger S. M., J. Chromatogr. B Analyt.
Technol. Biomed. Life Sci., 798, 231-239 (2003).

19) Albsmeier J., Schwedhelm E., Schulze F., Kastner M., Böger R. H., J. Chromatogr. B Analyt. Technol. Biomed. Life Sci., 809, 59-65 (2004).

20) Martens-Lobenhoffer J., Krug O., Bode-Böger S. M., J. Mass Spectrom., 39, 1287-1294 (2004).

21) Kirchherr H., Kühn-Velten W. N., Clin. Chem., 51, 249-252 (2005).

22) Schwedhelm E., Tan-Andresen J., Maas R., Riederer U., Schulze F., Böger R. H., Clin. Chem., 51, 1268-1271 (2005).

23) Martens-Lobenhoffer J., Bode-Böger S. M., Clin. Chem., 52, 488493 (2006).

24) Blackwell S., O’Reilly D. S., Talwar D. K., Clin. Chim. Acta, 401, 14-19 (2009).

25) Horowitz J. D., Heresztyn T., J. Chromatogr. B Analyt. Technol. Biomed. Life Sci., 851, 42-50 (2007).

26) Krzyzanowska K., Mittermayer F., Krugluger W., Schnack C., Hofer M., Wolzt M., Schernthaner G., Atherosclerosis, 189, 236-240 (2006).

27) Makino N., Maeda T., Sugano M., Satoh S., Watanabe R., Abe N., J. Diabetes Complicat., 19, 347-355 (2005).

28) Devangelio E., Santilli F., Formoso G., Ferroni P., Bucciarelli L., Michetti N., Clissa C., Ciabattoni G., Consoli A., Davì G., Free Radic. Biol. Med., 43, 511-518 (2007).

29) Fard A., Tuck C. H., Donis J. A., Sciacca R., Di Tullio M. R., Wu H. D., Bryant T. A., Chen N. T., Torres-Tamayo M., Ramasamy R., Berglund L., Ginsberg H. N., Homma S., Cannon P. J., Arterioscler. Thromb. Vasc. Biol., 20, 2039-2044 (2000).

30) Stühlinger M. C., Abbasi F., Chu J. W., Lamendola C., McLaughlin T. L., Cooke J. P., Reaven G. M., Tsao P. S., JAMA, 287, 1420-1426 (2002). 